\title{
Recompense as a factor in assigned punishment
}

\author{
Wilfried Hommers and Norman H. Anderson
}

\begin{abstract}
Children's judgements of deserved punishment were studied as function of three moral variables. Subjects judged how much a child in a story should be punished for ruining another's stamps, given information about $(a)$ how many stamps were damaged, $(b)$ the culpa, or intent, of the harmful act, and $(c)$ recompense, or the proportion of stamps paid back by the offender. In three experiments, recompense had substantially greater effects than the damage for which recompense was made. This pre-potency of recompense was greater at younger ages across a range from 4 years to college age. Damage and culpa were integrated by an additive rule in agreement with previous work. In contrast, the recompense-damage and recompense-culpa integration rules were both non-additive.
\end{abstract}

Just as there is a moral rule not to do harm, there is also one to undo harm that is done. This moral rule of reparation or recompense is well recognized in law and in everyday life. People who are responsible for harm may be expected or enjoined to make reparation. Although reparation is sometimes impossible or impracticable, the obligation to undo harm is generally explicit or implicit in moral judgement.

Despite its social importance, recompense has been little studied in previous work on moral judgement. Piaget (1965) contrasted two types of punishment: expiation and reciprocity. Expiation refers to punishment whose nature has an arbitrary relation to the offence except for being proportional in magnitude. Reciprocity refers to punishment that has some natural relation to the offence. Piaget's main conclusion was that there was a developmental trend from preference for punishment by expiation to punishment by reciprocity. This conclusion has been generally supported in subsequent work (see Lickona, 1976, pp. 226-229), but the number of studies on this issue is small.

Our approach differs from Piaget's in two main ways. The first is that we define the variable of recompense more narrowly than Piaget's concept of reciprocity. Reciprocity includes not only recompense, but also retaliation in kind. These two moral variables seem qualitatively different and deserve to be separated. The second difference is our use of information integration theory (Anderson, 1981). Moral judgements typically depend on several moral variables that act together. Recompense entails reference to the harm for which recompense is made. Psychological analysis of harm appears to depend on the intention or culpability of the harmdoer. Each moral variable must be integrated with the others in judgements about punishment. This kind of integration seems to be characteristic of moral judgements. The rules that govern the integration of multiple pieces of information are a central concern of information integration theory. Integration studies manipulate two or more stimulus variables, typically in factorial design. Response patterns in the factorial graphs provide clues about the structure of the integration rule. A pattern of parallelism, for example, suggests the operation of an adding or averaging rule (Anderson, 1980, 1981).

This integration theoretical approach has been applied to the classical intent-damage paradigm in a number of studies (Lane \& Anderson, 1976; Surber, 1977, 1982; Leon, 1980, 1982, in press; Grueneich, 1982; Hommers, 1983). These studies indicate that the two variables are integrated by an algebraic rule, which involves either adding or averaging. Our experiments extend this work to include the third moral variable of recompense.

In the study reported here, children and adults heard a story about a child who ruined 
some stamps belonging to a schoolmate. They were given information about three moral variables: the number of ruined stamps; the culpability of the child in the story; and the amount of recompense given by the child in the story. The task was to judge how much punishment this child deserved. Three experiments were run, using a very similar procedure. This common procedure is described first.

\section{Method and procedure}

Ruined stamp scenario. The subjects were first told a detailed background scenario about two children who collect stamps and who met one day at school to trade stamps. In the course of the trading, one child ruined some stamps belonging to the other child. The victim complained to the school superintendent, who asked the victim to decide on a fair punishment. Subjects were instructed to imagine that they themselves were the victim and to assign a fair punishment.

Stimulus design. Each subject judged 18 stories, all being completions of the background scenario that specified the level of three moral variables. These moral variables were employed in the following 2 (damage) $\times 3(\mathrm{culpa}) \times$ 3 (recompense) design.

The two levels of damage stated that two (or 10) stamps were ruined. The three levels of recompense stated that all (half, none) of the ruined stamps were paid back. The three levels of culpa described accidental, careless or intentional acts:

Accidental: 'He/she was very careful and used the pair of tweezers. He/she concentrated very much on handing you a stamp with the tweezers. But he/she did not see his/her glass of kool-aid and spilt it.'

Careless: 'The open inkpot stood on his/her side of the table. You told him/her about the danger. But, he/she left the inkpot there. Later on, he/she pushed against it and spilt it,'

Intentional: 'He/she wanted your best stamp. But, you did not wish to exchange your best stamp. He/she became furious and poured ink on your stamps.'

Practice. Subjects indicated deserved amount of spanking on a 20-point graphic rating scale. Scale usage was carefully explained during the practice phase. Two end-anchor stories were used initially to fix the extremes of the punishment scale, following the methodology of integration theory (Anderson, 1980). Given pictorially to facilitate understanding, the high end-anchor included: 12 ink-smeared stamps; the verbal statement of culpa that ' $\mathrm{He} / \mathrm{she}$ was jealous of your fine stamp collection and wished to destroy it. Suddenly, he/she poured ink on your stamps'; and no undamaged stamps as recompense, subjects being told that no recompense was given. The low end-anchor showed similarly one ink-smeared stamp; the culpa statement that 'Before he/she arrived you were alone looking at your stamps. You pushed against your kool-aid and spilt it"; and showed an undamaged stamp as recompense, subjects being told that the other child had two copies of the ruined stamp and gave one to the victim. High and low culpa information were also illustrated with a line drawing.

After the end-anchors were explained, 14 practice stories were given. These included four repetitions of the end-anchors and six stories from the main design so chosen that each stimulus level was included at least twice. This use of end-anchors and practice was designed to reduce response variability and to yield a linear (equal interval) response scale (Anderson, 1980, 1982, ch. 1).

\section{Experimental procedure}

The 18 stories from the main design were read by a female experimenter in separate random order for each subject. The sex of the children in the story was the same as that of the subject. Within each story, the initial sequence of information was culpa, damage and recompense, in that order. To minimize possible effects of order of presentation (Feldman et al., 1976; Anderson, 1981), this information was repeated in abbreviated form in the opposite order before judgement.

All subjects were run individually. Children were run in a laboratory van at their homes and received $\$ 1$ for a session lasting about 30 minutes. These children were from predominantly white, upper middle-class homes in the university area. The adult subjects were university students, volunteers fulfilling a course requirement in introductory psychology.

\section{Experiment 1}

This experiment was an initial look at the recompense variable. The subjects were 10 7 -year-olds with a mean age of 7:9 years ( $S D=4$ months) and 10 adults with a mean age of 18:6 years $(\mathrm{SD}=5$ months), half of either sex. 


\section{Experiment 2}

This experiment was run as a replication to verify the unexpectedly large effect of recompense found in the first experiment. The subjects were 10 6-year-olds (mean age 6:8 years, $\mathrm{SD}=2$ months) and 10 8-year-olds (mean age 8:7 years, $\mathrm{SD}=4$ months), half of either sex. In addition, each subject served in two identical sessions, about two weeks apart, in order to assess stability of the results.

\section{Results}

Two main results were obtained (see Figs 1 and 2). First, recompense had large effects, even larger than the effect of the damage for which recompense was made. Second, the integration of damage and culpa obeyed an additive rule, whereas the integration of each of these variables with recompense was non-additive. No significant main effect or interaction was obtained for sex in either experiment.

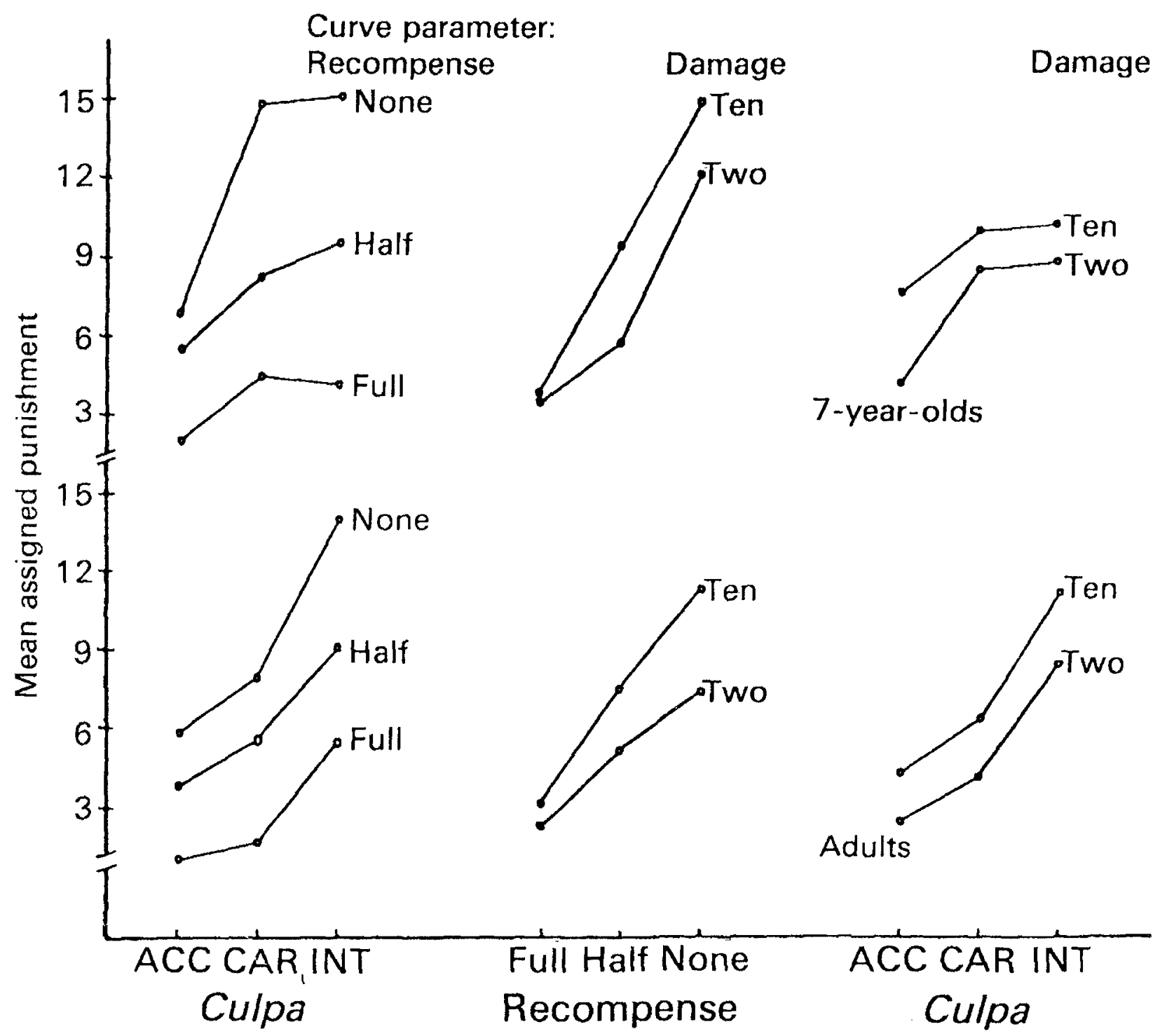

Figure 1. Assigned punishment as a function of three moral variables, Expt 1. Left panels show factorial graphs for recompense (curve parameter) and culpa (horizontal axis). Centre panels show factorial graphs for damage (curve parameter) and recompense (horizontal axis). Right panels show factorial graphs for damage (curve parameter) and culpa (horizontal axis). $\mathrm{ACC}=$ accidental; $\mathrm{CAR}=$ careless; $\mathrm{INT}=$ intentional. 
The data are presented in terms of factorial graphs, following the usual procedure in integration studies. The factorial graphs provide visual indices of the main effects and interactions; in addition they help to portray the integration rules.

Recompense. The most interesting results came from the recompense variable, which had larger effects than either culpa or damage. For the children of Expt 1, the recompense effect is visible as the vertical separation among the three curves in the upper left panel of Fig. 1. The top curve for no recompense shows much higher judgements of punishment than the bottom curve for full recompense. The bottom curve shows also that full recompense does not completely eliminate the punishment for carelessness or malicious intent in relation to accident. A somewhat smaller recompense effect appears for the adults, whose data are shown in the lower left panel. These recompense effects were significant both for children $(F=51.72$, d.f. $=2,18, P<0.001)$ and for adults $(F=28.69$, d.f. $=2,18$, $P<0.001$ ).

This statistical analysis may be supplemented by an index that expresses the recompense effect in terms of the marginal means of the factorial design, which correspond to the means of the curves in the left panels of Fig. 1. This index is the difference between the marginal means for no recompense and full recompense, which was 10.00 for children and 6.47 for adults. It expresses the recompense effect directly in terms of the actual punishment response itself.

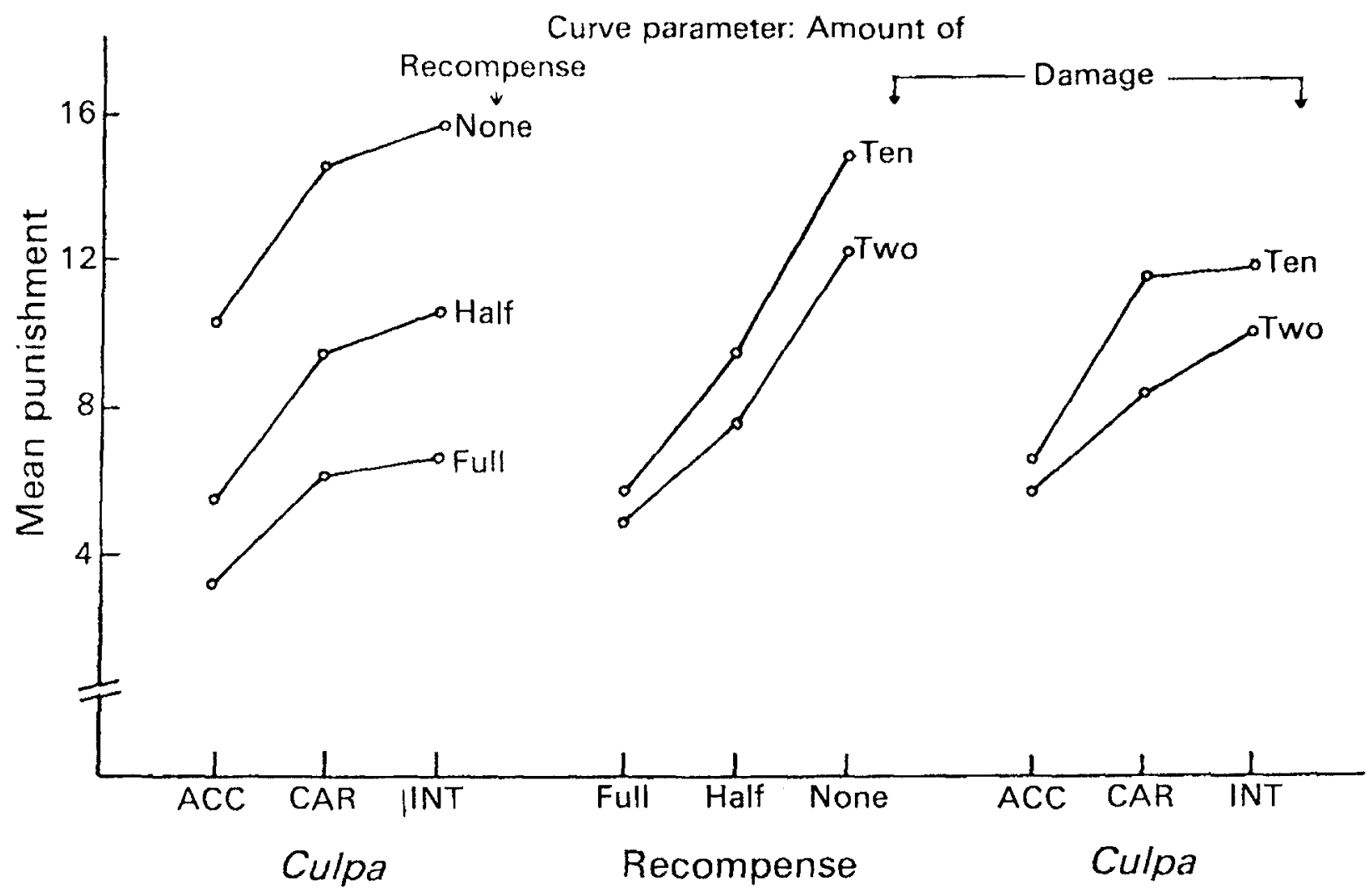

Figure 2. Assigned punishment as a function of three moral variables, Expt 2. Left panel shows factorial graph for recompense (curve parameter) and culpa (horizontal axis). Centre panel shows factorial graph for damage (curve parameter) and culpa (horizontal axis). Right panel shows factorial graphs for damage (curve parameter) and culpa (horizontal axis). $\mathrm{ACC}=$ accidental; $\mathrm{CAR}=$ careless; INT $=$ intentional.

Culpa. The culpa effect in Expt 1 is visible as the vertical range of each curve in the right panels of Fig. 1. These culpa effects were significant both for children $(F=17 \cdot 74$, d.f. $=2,18$, $P<0.001)$ and for adults $(F=49.76$, d.f. $=2,18, P<0.001)$. A culpa index was obtained by 
taking the difference between the marginal means for intentional and accidental damage in the factorial design. This index had the values of 3.33 for children and 5.97 for adults, expressed in terms of the punishment response scale.

Of interest here is the developmental trend in relative effect of culpa and recompense. For adults, the cited recompense and culpa effects were about equal, 6.47 and 5.97, respectively. For children, however, the culpa effect of 3.33 is much smaller, only a third of the value of 10.00 for recompense. This developmental trend is reflected in the significant age $\times$ culpa interaction that is discussed later.

It should be noted, of course, that comparisons between culpa and recompense are problematical because the observed effects of each variable depend on the specific levels chosen by the experimenter. This comparison is included in order to relate to previous work. It should be emphasized, however, that comparisons based on percentage of variance accounted for and similar indices are not generally valid (Anderson, 1982, section 6.1).

Damage. The effect of damage is visible as the vertical separation between the paired curves in the centre panels of Fig. 1. This damage effect was significant for children and adults $(F=24.91$ and 10.70 , respectively; d.f. $=1,9, P<0.01$ in both cases).

Damage had smaller effects than recompense. For children, the damage index in terms of the marginal means was 2.92 points on the punishment response scale. The recompense effect of 10.00 points cited previously was over three times as large. For adults, a similar somewhat less marked result was obtained, with recompense and damage effects of 6.47 and $3 \cdot 18$, respectively.

Replication. One important purpose of Expt 2 was to verify the unexpectedly large effect of recompense obtained in Expt 1. Comparison of Figs 1 and 2 shows that virtually identical results were obtained in both experiments. The format of Fig. 2 is the same as that of Fig. 1 and the pattern of results is virtually the same. The analysis of variance yielded significant results for all three 'moral' variables $(F=79 \cdot 06$, d.f. $=2,32, P<0.001$, for recompense; $F=40.42$, d.f. $=2,32, P<0.001$, for culpa; and $F=8.81$, d.f. $=1,16, P<0.01$ for damage).

The large recompense effect, in particular, appears to be reliable. As in Expt 1, the net effects of recompense and damage, 8.23 and 1.89 , respectively, stand in a ratio of approximately four to one.

The effects of recompense and of damage can be compared because both variables are defined in terms of number of stamps. A qualification is required, however, to the foregoing comparison because the absolute range of recompense, from 0 to 10 stamps, is greater than the absolute range of damage, from 2 to 10 stamps. A conservative comparison may be obtained by using only the data for half and full recompense. Even for this restricted range the recompense effect is markedly larger than the damage effect. For children, these effects were 4.15 and 2.92 for recompense and damage in Expt 1 , and 3.21 and 1.89 for recompense and damage in Expt 2.

Integration rules. Judgements in these experiments reflect the combined action of all three moral variables. Three pieces of information have to be integrated to reach a moral judgement. It is of interest, therefore, to see whether the moral information is integrated by some simple rule.

The key to determining the integration rules is the pattern in the factorial graphs. A pattern of parallelism implies an additive rule, whereas different patterns of non-parallelism imply different forms of non-additive rule. Our main concern was whether integration is additive or non-additive. A statistical test is available from the analysis of variance: a 
significant interaction term represents significant deviations from paralleism. For the most part, however, visual inspection of the factorial graphs is sufficient.

The culpa-damage integration obeys an adding-type rule: punishment $=c u l p a+$ damage . This is shown by the near-parallelism of the paired curves in the right panels of Figs 1 and 2. None of three interaction tests approached significance. This rule has already been well established in previous work (see Leon, 1980; Grueneich, 1982). Its main value now is to demonstrate that our task and procedure are comparable to those used previously.

In contrast the damage-recompense integration is non-additive; this is shown by the non-parallelism in the centre panels of Figs 1 and 2. The deviations from parallelism are not large, but all are statistically significant. The interaction tests yielded $F=4.42$ and 4.80 , d.f. $=2,18, P<0.05$, for children and adults in Expt 1 and $F=4.82$, d.f. $=2,32, P<0.05$, for children in Expt 2.

The culpa-recompense integration also appears to be non-additive, although these data are not as clear. The deviations from parallelism were significant only for the adults of Expt 1 and the children of Expt $2(F=3 \cdot 54$, d.f. $=4,36, P<0 \cdot 05$, and $F=2 \cdot 65$, d.f. $=4,64$, $P<0.05$, respectively). However, inspection shows marked non-parallelism of the same pattern in all three factorial graphs. These results suggest that recompense introduces a general source of non-additivity in moral judgement.

Cross-age comparisons. Both the age $\times$ culpa and the age $\times$ recompense interactions in Expt 1 were significant $(F=10.64$ and 4.25 , respectively, d.f. $=2,36, P<0.05$ in both cases). In contrast, no effects of sex were significant in any analysis. The age $\times$ culpa interaction appears as the difference in pattern of the two graphs at the right side of Fig. 1. Compared to the adults, the children's data show lesser vertical range of the culpa curves and near-equality of the response to careless and intentional damage. The age $\times$ recompense interaction appears as the greater slope of the children's curves in the centre panels of Fig. 1.

Two post-tests were done to support the interpretation of the two age interactions. First, the six rating differences between 'full' recompense stimuli and 'none' recompense stimuli were calculated for each subject. These differences measure the recompense effects on each culpa $\times$ damage combination. The main effect of the age group on these differences turned out to be significant $(F=5 \cdot 34$, d.f. $=1,18, P<0 \cdot 05)$. Thus, adults appeared to have a smaller recompense effect than children as the factorial graphs indicate. Second, the six rating differences between 'intentional' culpa stimuli and 'accidental' culpa stimuli were calculated for each subject, in the same way as before. These differences measure the culpa effect sizes on each recompense $\times$ damage combination. The main effect of the age group on these differences also turned out to be significant $(F=8.78$, d.f. $=1,18, P<0.01)$. Thus, the adults appeared to have a larger culpa effect than the children as the factorial graphs also indicate.

It deserves emphasis that the patterns of response from the integration task imply that the age interactions are genuine. An alternative interpretation of the age $\times$ recompense interaction is that the children merely used a larger range of response. This interpretation, however, can be eliminated by inspection of the left panels of Fig. 1, which show equivalent ranges of children and adults, and the right panels, which show a smaller range for children. Moreover, the main effects for culpa and damage are both less for the children. Indeed, the smaller damage effect for children underscores their greater recompense effect, which cannot be interpreted as an equal proportion of a larger damage. 


\section{Experiment 3}

The main purpose of this experiment was to extend the study of the recompense effect to younger children. The procedure was the same as before but the task was simplified and the instructions expanded in several ways to make the task meaningful to 4-5-year-olds.

\section{Method}

Design. The main design change was from the three-factor to simpler two-factor designs; these require integration of only two pieces of given information. The 3 (recompense) $\times 3$ (culpa) design used the factor levels of Expts 1 and 2 . The 3 (recompense) $\times 3$ (damage) design used the same levels of recompense, together with damage levels of two, six and 12 ruined stamps. Also, the stimulus levels of the recompense $\times$ culpa design were presented singly, an even simpler task that requires no integration.

Both damage and recompense were presented verbally as well as in concrete visual form, as the appropriate numbers of ruined and sound stamps. Because the damage effect had been small in the previous experiments, an attempt was made to amplify it by confounding number of stamps with size, colouring, and concreteness of design.

Procedure. Each child was first familiarized in detail with the hobby of stamp collecting, using an introductory guide issued by the US post office. In addition, the use of a tweezers was demonstrated to each child, and ruined and sound stamps were illustrated and explained. Following this, the scenario of the previous experiments was introduced and a similar practice session was given. General procedure was very similar to that of Expts 1 and 2 . In particular, the two pieces of information in each story were always presented a second time in abbreviated form in reverse order before subjects responded. In addition, as already noted, the concrete stimuli for recompense and damage were presented visually for further control of possible order effects.

The main concern in this experiment was with the damage-recompense integration. Accordingly, the initial session included two replications of the recompense $x$ damage design for each child. For the 9-year-olds, the session was continued to include a single presentation of the recompense $\times$ culpa design. The 4-5-year-olds, however, received the latter design in a second session about two weeks later.

Subjects were $194-5$-year-olds (mean age $=4: 10$ years, $S D=6$ months) and six 9-year-olds (mean age $=9: 8$ years, $S D=4$ months) from the same population as in Exp1 1. One other 4-year-old could not be contacted for the second session. The 9-year-olds were included mainly as a check for comparison with the older subjects in the previous experiments. Primary interest was on the judgements of the 4-5-year-olds.

\section{Results}

Recompense and damage. The 4-5-year-olds showed a very large recompense effect, as demonstrated by the large vertical separation among the curves in the left panel of Fig. 3. In terms of the marginal means, the overall effect of recompense was $12 \cdot 73$, a value that was essentially the same for both replications. However, the curves are nearly flat, which indicates small effects of damage. Even for the top curve, which shows a pure effect of damage without any recompense, the overall damage effect is only $2 \cdot 75$, much less than the effect of recompense, even if the half and full recompense conditions are compared. At this young age, therefore, the recompense effect is accentuated.

The data for the 9-year-olds, given in the right panel of Fig. 3, are very similar in pattern to those obtained in the two previous experiments. Here again, the recompense effect is larger than the damage effect, and the curves show significant non-additivity $(F=7 \cdot 44$, d.f. $=4,20, P<0.001$ ).

The statistical test of the recompense $\times$ damage interaction of the $4-5$-year-olds was also significant $(F=3.37$, d.f. $=4,72, P<0.05)$. Even at this young age, therefore, recompense appears to involve a non-additive component. Since the pattern of the non-additivity for the youngest age group seemed to differ from that for the other age groups a post-test inspection of the damage-recompense interaction was carried out.

Differences of individual ratings between the damage levels of 12 ruined stamps and two ruined stamps were compared on each recompense level separately. In the 'none' recompense condition these differences were significantly larger than in the 'half' recompense condition and they were also significantly larger than in the 'full' recompense condition (Wilcoxon's test for matched groups: $t=47, n=20, P<0 \cdot 05$; and $t=36 \cdot 5, n=20$, $P<0.01$, for both conditions respectively). Moreover, 11 children changed from an increase 
4-5-year-olds

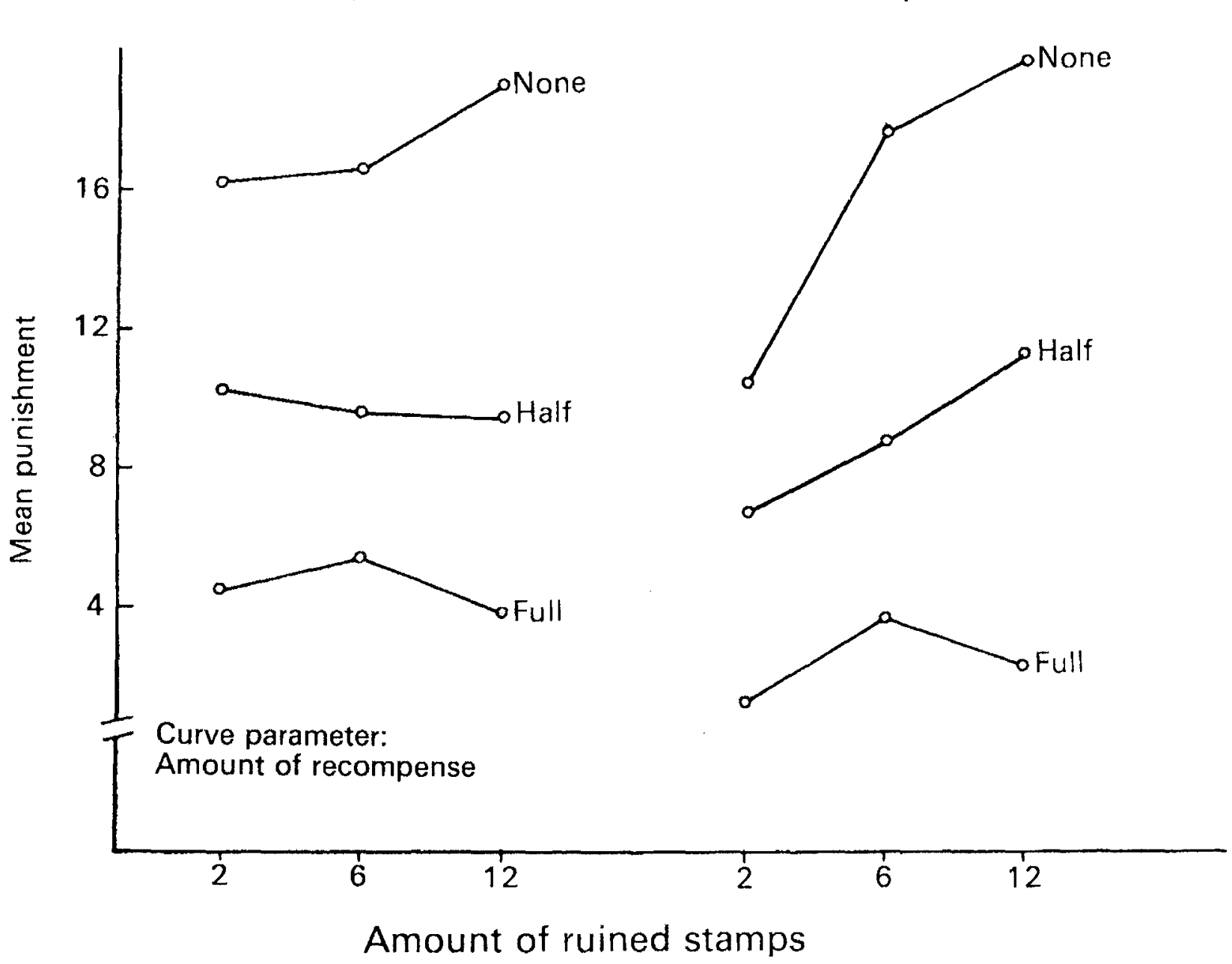

9-year-olds 


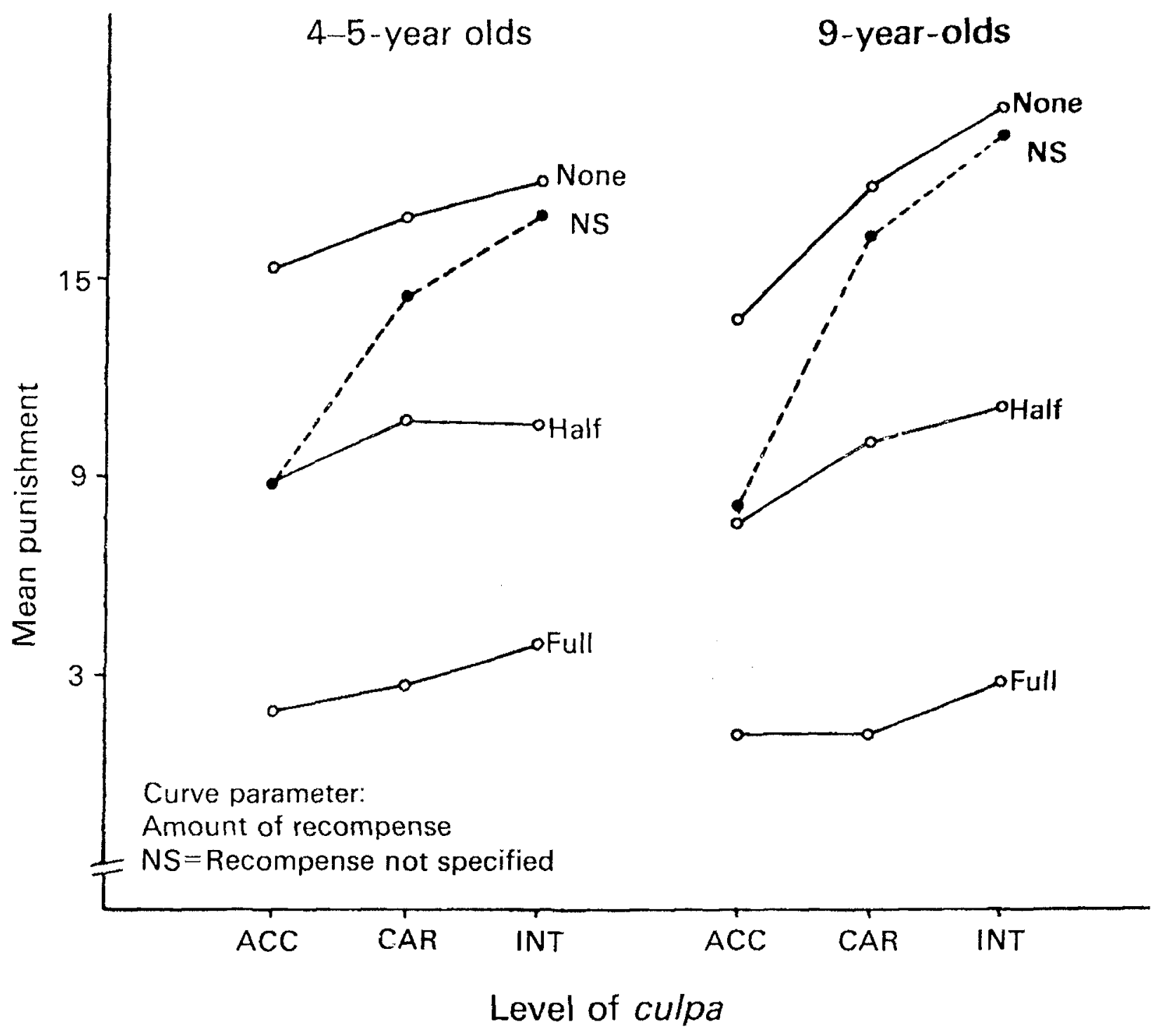

Figure 4. Assigned punishment as a function of culpa (horizontal axis) and recompense (curve parameter) for preschoolers (left panel) and 9-year-olds (right panel). $\mathrm{ACC}=$ accidental; $\mathrm{CAR}=$ careless; $\mathrm{INT}=$ intentional.

the culpa information. Culpa has substantial effects when presented alone, as shown by the dashed-line curve for culpa information without specified recompense. Thus, the small relative effect of culpa reflects the preponderant weight given to the recompense information. The main outcome of this experiment, therefore, is that the large effect of recompense is already present at 4 years of age.

As in Expts 1 and 2 the non-additivity of the recompense-culpa integration rule is not definitely supported by the data analysis although the graphs of Fig. 4 show some divergence of the curves. The recompense $\times$ culpa interaction was clearly not significant for the 4-5-year-olds $(F=0 \cdot 34$, d.f. $=4,72)$. However, this interaction approached significance on the 5 per cent level for the 9-year-olds $(F=2 \cdot 81$, d.f. $=4,20)$. That lack of significance may be due to a lack of power of the statistical test. Nevertheless, a somewhat speculative interpretation of these results may be offered. Overall the indefinite support for the non-additivity of the recompense culpa integration may indicate that the non-additivity of recompense may develop depending on the information to be combined with recompense. In combination with damage the non-additivity appeared with lower age and was definitely supported by the statistical analysis, possibly indicating its quick or frequent onset. In combination with culpa the non-additivity may appear with decalage. Thus, with respect to 
the culpa-recompense integration, additive and non-additive integration rules may exist side by side in certain samples of age groups. That may have the effect that the occurrence of a significant non-additivity in a group analysis depends on the sampling of the subjects. Thus, single-subject analysis using several runs for each subject would be necessary in future research with larger sample sizes.

Order effects. As already noted, order effects can be important in the theoretical interpretation of moral judgement. Accordingly, various steps were taken to reduce or eliminate possible effects of order of presentation. In Expts 1 and 2, the three pieces of information were repeated in the opposite order to equalize attention, which is known to be a major determinant of order effects (see Anderson, 1981, section 3.3). Additional steps were taken in Expt 3 by using only two pieces of information and by simultaneous visual presentation of the damage and recompense stimuli. However, the same pattern of results was obtained in Expt 3. These considerations suggest that order effects could not account for the large recompense effect.

With respect to integration rules, available evidence suggests that their form may not be affected by order of presentation. This is a major conclusion of Grueneich (1982), who studied intent-damage integration by children, and Surber's (1982) analyses point to the same conclusion. With adults, a series of three experiments by Hommers \& Anderson (in preparation) has found no difference between the natural culpa damage-recompense order and two other sequences in which recompense occupied the middle position. The stimulus values were the same for the three sequences of presentation, and the integration rules were all similar to those reported here. In particular, the recompense-damage and recompense-culpa integration rules were uniformly and markedly non-additive.

\section{General discussion}

\section{Recompense effect}

All three experiments show that recompense has a predominant influence on moral judgement. Indeed, the effect of recompense appeared to be larger than the effects of damage for which recompense was made. No less surprising, the recompense-damage disproportion was greater at younger ages. The effect of recompense seems general. It was obtained at all age levels across three experiments and it did not appear to be a novelty effect, for it was accentuated in the second session of Expt 2. Nor can it be attributed to the order of stimulus presentation for the reasons already discussed in Expt 3 . Thus, it seems reasonable to consider this recompense effect as genuine. Although the age trend seems to disagree with the views of Piaget (1965), it seems consistent with the striking direct evidence for its early development obtained by Zahn-Waxler et al. (1979), who found substantial frequency of reparation behaviour by children of $1 \frac{1}{2}-2 \frac{1}{2}$ years of age in home settings.

One natural interpretation of our results is that recompense has two components. One of them is undoing harm; that is the specific function of reparation and has its locus in the victim. The second of them has its locus in the harmdoer, with recompense being a positive moral action that reduces blame. The second component could account for the recompense-damage disproportion.

A possible objection to this two-component interpretation is that the second component must be fairly large to account for the observed disproportion. It might seem doubtful that undoing a small amount of damage could confer much positive moral value. However, Leon (1982) has found substantial effects from saying 'I'm sorry', which makes no material reparation, and similar results have been obtained by Darby \& Schlenker (1982). Most of 
Leon's subjects obeyed an additive rule, moreover, which implies that the apology effect was independent of amount of damage. The two-component interpretation thus appears consistent with available data.

\section{Integration rules}

An additive integration-punishment $=c u l p a+$ damage - is indicated by the pattern of parallelism for the culpa $\times$ damage graphs of Expts 1 and 2. This result agrees with much other work on the classical intent damage issue (see Leon, 1980, 1982; Grueneich, 1982; Surber, 1982). The present term, culpa, has been suggested by Hommers (1983) as being more appropriate than intent to include such concepts as carelessness and negligence.

Diverging fan patterns were obtained for both the recompense $\times$ damage and the recompense $\times$ culpa graphs. This implies a non-additive integration that, because of the parallelism of the damage $\times$ culpa graphs, is localized in the recompense variable. The fan pattern, however, is consistent with either of two common integration rules: a multiplying rule or an averaging rule with differential weighting (Anderson, 1981, p. 45). The experiments were not designed to distinguish between these two integration rules. Further work on this question may find it preferable to vary recompense in absolute rather than proportional fashion and to separate the two components of recompense experimentally as in the pioneering, solitary effort of Berscheid \& Walster (1967).

\section{Acknowledgements}

This research was performed during the first author's stay at the Center for Human Information Processing, University of California, San Diego, 1978-1979, which was made possible by a grant from the Stiftung Volkswagenwerk, Hannover, Federal Republic of Germany. Support was also given by National Science Foundation Grants BNS79-04675 and BNS82-12461 to Norman H. Anderson. We wish to thank Ellen Himmel for assistance in running subjects and also the children and their parents who cooperated in this research.

\section{References}

Anderson, N. H. (1980). Information integration theory in developmental psychology. In F. Wilkening, J. Becker \& T. Trabasso (eds), Information Integration by Children. Hillsdale, NJ: Erlbaum.

Anderson, N. H. (1981). Foundations of Information Integration Theory. New York: Academic Press.

Anderson, N. H. (1982). Methods of Information Integration Theory. New York: Academic Press.

Berscheid, E. \& Walster, E. (1967). When does a harm-doer compensate a victim? Journal of Personality and Social Psychology, 6, 435-441.

Darby, B. W. \& Schlenker, B. R. (1982). Children's reactions to apologies. Journal of Personality and Social Psychology, 43, 742-753.

Feldman, N. S., Klosson, E. C., Parsons, J. E., Rholes, W. S. \& Ruble, D. N. (1976). Order of information presentation and children's moral judgments. Child Development, 47, 556-559.

Grueneich, R. (1982). The development of children's integration rules for making moral judgments. Child Development, 53, 887-894.

Hommers, W. (1983). Die Entwicklungspsychologie der Delikts- und Geschäftsfähigkeit. Göttingen: Hogrefe.

Hommers, W. \& Anderson, N. H. (in preparation). Moral algebra of recompense. In N. H. Anderson (ed.), Contributions to Information Integration Theory.

Lane, J. \& Anderson, N. H. (1976). Integration of intention and outcome in moral judgment. Memory and Cognition, 4, 1-5.

Leon, M. (1980). Integration of intent and consequence information in children's moral judgments. In F. Wilkening, J. Becker \& T. Trabasso (eds), Information Integration by Children. Hillsdale, NJ: Erlbaum.

Leon, M. (1982). Rules in children's moral judgments: Integration of intent, damage, and rationale information. Developmental Psychology, 18, 835-842.

Leon, M. (in press). The rules mothers and sons use to integrate intent and damage information in their moral judgment. Child Development, 55.

Lickona, T. (1976). Research on Piaget's theory of moral development. In T. Lickona (ed.), Moral Development and Behavior. New York: Holt, Rinehart \& Winston.

Piaget, J. (1965). The Moral Judgment of the Child (translated by M. Gabain). New York: The Free Press (originally published 1932).

Surber, C. F. (1977). Developmental processes in social inference: Averaging of intentions and consequences in moral judgment. Developmental Psychology, 13, 654-665. 
Surber, C. F. (1982). Separable effects of motives, consequences, and presentation order on children's moral judgments. Developmental Psychology, 18, 257-266.

Zahn-Waxler, C., Radke-Yarrow, M. \& King, R. A. (1979). Child rearing and children's prosocial initiations toward victims of distress. Child Development, 50, $319-330$.

Received 23 January 1984; revised version received 27 June 1984

Requests for reprints should be addressed either to Wilfried Hommers, Institut für Psychologie, der Unjversität Würzburg, Domerschultstraße 13, 8700 Würzburg, Federal Republic of Germany; or to Norman H. Anderson, Psychology C-009, University of California, La Jolla, CA 92093, USA. 